\title{
FILOSOFIA SCHOPENHAUERIANA \\ E LITERATURA MACHADIANA: EM TORNO DO CONTO "NOITE DE ALMIRANTE"
}

\author{
Jair Lopes BARBOZA ${ }^{1}$
}

- RESUMO: Trata-se neste artigo de mostrar como se dá a recepção de alguns elementos da filosofia schopenhaueriana, como a oposição entre intelecto e vontade, na literatura de Machado de Assis. Com efeito, examinado o conto "Noite de almirante", pode-se dizer que a personagem Genoveva faz as vezes da vontade, ao passo que Deolindo é guiado pelo intelecto.

- PALAVRAS-CHAVE: Schopenhauer; Machado de Assis; intelecto; vontade.

\section{Resumo do conto "Noite de almirante"}

O marujo Deolindo retorna ao Rio de Janeiro depois de uma longa viagem de instrução numa corveta. Sôfrego de saudades e alimentando sonhos de amor, sai ao encontro da amada que deixara em terra, Genoveva. A paixão entre ambos começara antes da partida da corveta. Genoveva, definida pelo narrador como a "caboclinha de vinte anos, esperta, olho negro e atrevido", jurara esperar pelo amado. Ele, por sua vez, the retribuiria, não se envolvendo com mulher alguma por esses mares afora. Foi um juramento de fidelidade recíproca.

Dez meses depois volta a corveta. Deolindo vai ver Genoveva. Recorda-se no caminho que não fez caso de nenhuma mulher. Levava um par de brincos para Genoveva. Qual não foi o seu espanto ao avistar a velha Inácia, com quem a amada morava, e ela lhe informar que Genoveva andava

1 Doutor em Filosofia pelo Departamento de Filosofia da USP e tradutor de Schopenhauer. 
de cabeça virada, por conta do mascate José Diogo. Deolindo ouve estupefato as palavras da velha: "Não imagina a paixão que eles têm um pelo outro". Genoveva mudara de amor e endereço.

Deolindo ruma para o novo endereço, arquitetando cenas de sangue. Da janela, Genoveva reconhece Deolindo e o faz entrar. Nenhuma comoção ou intimidade demonstra. Ela admite que agora gosta de outro. O coração, justifica, mudou, apesar de ela pensar no marujo. O marujo, entretanto, cita o juramento de despedida que ambos fizeram. Ela retruca que na ocasião em que jurou era verdade, mas vieram outros tempos, o mascate, e ela se apaixonou por este como se apaixonara por Deolindo. $\mathrm{O}$ narrador comenta que faltava o padrão moral das ações à cabocla. Deolindo não o percebe e insiste na fidelidade perdida. Não obtendo o retorno de Genoveva, resta-lhe sair da casa, acompanhado por ela. Deolindo despede-se cabisbaixo, lento, de ar velho e triste. Dissera a Genoveva que ia se matar. Mas não o faz. A planejada noite de almirante com a cabocla tornou-se apenas uma mentira para os marujos que o abordavam.

O conto, assim, revela uma tensão entre moral - juras de amor - e inclinações volitivas, refratárias a ela.

\section{I}

Em 1881, num escrito intitulado Cherchez la femme, Machado de Assis trai as suas leituras schopenhauerianas (assim como já o fizera em 1880 no decorrer, e principalmente no final, de Memórias póstumas de Brás $\left(u b a s^{2}\right.$ ) ao dizer que - sinal de que leu muita filosofia, pois somente assim um espírito da sua envergadura arriscar-se-ia a uma semelhante sentença: "sustentar a originalidade de um pensador"; apenas quem transitou por muitas filosofias, e as comparou, pode, dentro de um amplo universo teórico, pronunciar-se sobre a originalidade de uma delas - "se devemos aceitar a original teoria de um filósofo, ela [a mulher] é quem transmite a porção intelectual do homem" (Machado de Assis, 1994, v.3, p.1003).

O estudioso da história da filosofia sabe que este não-nomeado é Arthur Schopenhauer, cuja citação completa afirma que o intelecto é um acidente na formação do organismo, é uma parte secundária, ficando

2 Logo a seguir trataremos em detalhe do assunto. 
reservada ao sexo masculino a contribuição fundamental para a constituição do ser humano, ou seja, é ele quem transmite à nova vida a substância, a essência íntima, o caráter inteligível, o em-si, que é nomeado de vontade. Schopenhauer diz:

então admitiremos ... que, na procriação, o pai, como sexus potior e como princípio procriador, confere a base, o radical da nova vida, portanto a vontade; a mãe, entretanto, como sexus sequior e princípio que meramente concebe, confere o secundário, o intelecto; por conseguinte, o homem herda do pai seu aspecto moral, seu caráter, suas tendências, seu coração; da mãe, em contrapartida, o grau, a característica e a orientação da sua inteligência. (Schopenhauer, 1972a, cap.43, p.592).

Essa referência ao filósofo germânico num texto de 1881 sem dúvida nos autoriza a procurar nas entrelinhas de textos machadianos posteriores, e mesmo de um quase contemporâneo, como as Memórias..., de 1880, a presença de Schopenhauer nos escritos do grande escritor carioca. ${ }^{3}$ Ao encerrar as suas memórias lá do outro mundo, Brás Cubas declara que não transmitiu à posteridade o "legado da nossa miséria": não gerou outra criatura, não se perpetuou em filhos, em nova vida, esta que, ao ser tomada como "miséria" (Brás usa o pronome "nossa"; ou seja, ele se refere à humanidade inteira, e não exclusivamente a si mesmo), deixa-nos entrever no pensamento do narrador a visão pessimista de mundo. Visão que aponta a miséria, o sofrer como predicado inseparável da vida, remetendo assim a Schopenhauer e ao seu ponto de partida ético-filosófico, ou seja, à concepção da vida enquanto expiação; logo, remetendo a uma visão cuja raiz é o pessimismo - a expressar-se de modo lapidar na frase "alles Leben Leiden ist" ["toda vida é sofrimento"].

Brás Cubas, na página introdutória das suas memórias, até se pergunta se não haveria metido em sua obra "algumas rabugens de pessimismo". Dúvida apenas retórica, pois logo depois, no decorrer da narrativa, encontraremos a confirmação. No próprio prólogo à quarta edição, Machado de Assis se faz porta-voz do defunto autor, e sentencia:

O que faz meu Brás Cubas um autor particular é o que ele chama "rabugens de pessimismo". Há na alma deste livro, por mais risonho que pareça, um

3 Não devemos nos esquecer de uma crônica, intitulada "O autor de si mesmo", em que Machado parodia a metafísica do amor sexual de Schopenhauer, e ainda aproveita para, de roldão, ironizar Hegel, que era considerado por Schopenhauer o seu grande adversário na filosofia alemã da época. 
sentimento amargo e áspero, que está longe de vir dos seus modelos. (Machado de Assis, s. d., p.33)

Mas é antes em Schopenhauer que se encontra o molde pessimista de Brás. Para aquele a vida de fato é miséria, visto que o sofrimento é o que lhe é mais nuclear. Para o autor de $O$ mundo como vontade e como representação, obra lida por Machado, a coisa-em-si de todo indivíduo, o íntimo do seu corpo, a sua essência, é a vontade, que se define como "Selbstentzweiung" (autodiscórdia); o que vale dizer que ela é um conflito intrínseco consigo mesma, a projetar-se pelo mundo natural por meio de lutas, seja do indivíduo consigo mesmo, contra outros ou entre as espécies, todos à procura de domínios onde o si-mesmo volitivo possa manifestar-se. No corpo humano, à discórdia essencial associa-se a miríade sem fim de desejos, impossíveis de ser todos satisfeitos, já que "contra cada desejo satisfeito permanecem contra ele pelo menos dez que não o são" (Schopenhauer, 1972b, §38, p.230-1). Assim, o estado natural de todo indivíduo, além do egoísmo para se auto-afirmar enquanto centro do universo, são os desejos que manifestam a sua vontade, os quais o impulsionam para a satisfação dos interesses. Precisamente a partir do casamento entre desejo e egoísmo, surge a condição miserável do homem, a sua renovada carência, isto é, a impossibilidade de satisfação definitiva de todos os apetites. Carência - e Brás Cubas expressa a carência a mais essencial, do ponto de vista da espécie humana, o desejo não realizado de ter um filho -, ou sofrimento, significa positividade: nós a sentimos vivamente, com inteira consciência, enquanto a satisfação é negativa, fazendo-se clara quase sempre por recordação, quando já terminou.

Mas não é apenas nas palavras finais das Memórias... que podemos identificar as ressonâncias da leitura de Schopenhauer em Machado de Assis. Antes, no transcorrer da narração, registra-se o tratamento literário de um tema filosófico dos mais caros ao filósofo germânico. Estamos falando do tema da oposição entre intelecto e vontade. Esta é o prius de cada ser humano, reina sobre o intelecto, embora este procure, de modo vão, antecipar-se a ela por resoluções racionais. Mas não adianta, o intelecto, para Schopenhauer, é um servo da vontade, é um ginete sobre um cavalo, que pode sim muitas vezes conduzi-lo; só que há momentos em que o cavalo, por si só, soberanamente, decide a direção da cavalgadura, sem dar atenção ao ginete. No capítulo das Memórias... intitulado "O almocreve", Brás nos narra um acidente que poderia ter sido dos mais graves na sua vida, podendo até mesmo tê-lo levado à morte. Deu-se quando tentava montar um jumento, que empacou. Esforçou-se por tirá-lo do lugar, mas o animal recusou-se e o sacudiu fora da sela, 
fazendo que seu pé ficasse preso ao estribo. Se o bicho disparasse estrada afora, o herói estaria perdido. Eis que surge um almocreve e segura a besta... Imensamente agradecido por ter sido salvo de um grave acidente, Brás resolve dar uma recompensa àquele homem prestativo. A princípio três moedas de ouro. Só que, quando vai pegá-las, a idéia dá uma cambalhota no trapézio da mente, e o valor é rebaixado para duas moedas. Passa um tempo, e outra cambalhota, resultado: uma moeda. Por fim, decide-se Brás por um cruzado de prata. Todavia, o mais curioso vem depois: o herói sente que na verdade deveria ter dado apenas alguns vinténs de cobre; o almocreve ficaria imensamente satisfeito com tal quantia. Ora, o que essa cena evidencia é que, no fundo, a vontade do protagonista era simplesmente não dar quase nada. É compelido a contribuir provavelmente por conta de algum motivo abstrato, algo assim como um mandamento ou regra de boa conduta, que prescreve a contribuição para aqueles que nos ajudaram. Brás cogita, raciocina por empréstimo, faz uso das representações adquiridas, mas, de um modo mais fundo, essencial, a sua vontade se choca contra a sua resolução. Tanto é que, mais tarde, a vontade vence: Brás se arrepende do minguado valor que dera, exatamente porque sua vontade, soberana, tendo readquirido a direção da conduta, reclama acerca de uma ilusão passada. É como se tivesse sido enganada, e queria ser outra, ou seja, queria que a decisão tomada fosse diferente, queria modificar algo que se deu exclusivamente por conta de uma ilusão intelectual. Se houve arrependimento, é porque a vontade de Brás, mesmo depois do ato praticado, é soberana e se faz imperiosa enquanto insatisfação.

Em "Noite de almirante", essa oposição entre vontade e intelecto, entre natureza e artifício, espontaneidade volitiva e artifício moral, evidenciada nas memórias, é ainda mais marcante, em virtude da concentração narrativa da forma conto. Tal oposição se traduz na inclinação amorosa de Genoveva por um novo amor, abandonando as juras contraídas com o marujo Deolindo, que saíra mar afora em viagem de instrução. A situação entre esses dois amantes será mais bem entendida, em vista do nosso propósito; isto é, mostrar que existe comunicação entre estruturas conceituais da filosofia schopenhaueriana e a literatura machadiana, se tomarmos agora como fio condutor a crítica de Schopenhauer à moral 
kantiana, ancorada num sollen (tu deves), por sua vez a cristalizarse no imperativo categórico cuja principal função é gerenciar o convívio social.

Kant dizia que o valor moral de cada sujeito residiria numa ação modelar, a partir de um imperativo categórico, não-contraditório consigo mesmo, e que transformaria essa ação numa lei universal. Sempre que agisse, deveria o sujeito perguntar-se se a máxima da sua ação seria ou não aceitável, caso se transformasse numa lei universal. Tratar-se-ia aqui também de colocar em primeiro plano o velho mandamento cristão, que reza não fazermos a outrem aquilo que não desejamos que façam a nós mesmos. Assim, diante da possibilidade de uma promessa mentirosa - e Genoveva mente nas suas juras de amor, ao não reservar o seu coração para Deolindo, como havia prometido -, deveria o sujeito perguntar-se se essa mentira seria aceitável, ainda que para livrá-lo de uma dificuldade. Kant se antecipa e diz que não: pois todos notarão que até se pode mentir, mas não querer que tal ato se transforme numa lei universal; caso contrário, não haveria mais espaço para promessas, pelo menos as confiáveis, porque nenhuma palavra empenhada em relação ao futuro seria digna de crédito. Sem falar que o próprio mentiroso estaria implicitamente admitindo ser pago na mesma moeda: por conseguinte a minha máxima, uma vez arvorada em lei universal, destruir-se-ia a si mesma.

Do mesmo modo no suicídio. O suicida não pode agir por imperativo categórico, pois estará querendo o fim da humanidade. Logo, sua ação será contraditória, apontará para o fim do próprio indivíduo que age por máximas racionais.

Segundo Schopenhauer, o quixotismo dessa moral em moldes kantianos salta aos olhos. Reside em prescrever uma regra, como se fosse possível ao indivíduo, pelo seu intelecto (sede da razão), antes de qualquer ação, refletir sobre o seu agir e, daí, procurar a universalidade não contraditória desse agir. É como se cada um tivesse em sua mente um grande olho crítico-moral para observar e julgar a retidão dos atos, pesando as conseqüências que eles trariam. Em relação ao nosso conto, seria como se Genoveva, com sua consciência moral, pudesse prometer fidelidade amorosa a Deolindo a partir de suas juras e, refletidamente, fiel a estas, constituísse uma lei universal. Genoveva calculadamente evitaria que o desejo emigrasse para outro objeto amoroso, esperaria pelo retorno de Deolindo, mesmo se à custa de renúncias e violência à sensibilidade, mesmo se à custa de violência às inclinações, aos interesses sensuais violência que em última instância todo imperativo categórico requer. $\mathrm{Na}$ possível atitude de fidelidade de Genoveva estaria uma visão de humani- 
dade: que valeria para todos. Genoveva, a virtuosa, a Penélope dos trópicos, quereria uma humanidade retamente cumpridora dos seus pactos amorosos. Todavia, se isso fosse realmente possível, diria Schopenhauer, seria como se a natureza, os impulsos, a vontade, a própria substância de cada um pudesse vergar-se diante do acidente, diante do intelecto e suas resoluções. Mas isso não é possível, porque o intelecto é secundário, acidental, primária sim é a vontade. Afirmar o contrário é defender que o simples fenômeno possa adquirir poder sobre a coisa-em-si. Em linguagem de Freud (outro leitor de Schopenhauer), seria como atribuir uma eficácia desmesurada ao Superego sobre o Id, do superficial consciente sobre o mais fundo inconsciente. Do ponto de vista da filosofia schopenhaueriana, tais observações soam irreais, pois a natureza não se verga diante de uma inadequada ética prescritiva, ela sempre se rebela contra semelhantes tentativas. A experiência mostra que as resoluções do intelecto se vergam diante do prius do homem, a vontade, caso não se ajustem a esta. Se a vontade decide em contrário - como na cena da gratificação das Memórias...: não adiantou Brás decidir recompensar o almocreve com um valor alto, o seu íntimo desejo era dar pouco, nada mesmo, como comprova o remorso -, só resta ao intelecto assentir. Se um cavalo toma uma curva, será vã a tentativa do ginete em conduzi-lo por caminho diferente. Contraiam-se quantas juras se quiser, façam-se quantos contratos se quiser (Deolindo e Genoveva celebraram um contrato amoroso), montem-se quantos imperativos se quiser - na hora da ação efetiva, dos atos decisivos, caem a prescrição e os imperativos inadequados, prevalecendo os interesses da vontade. Por outros termos, o que importa para o indivíduo é a decisão que melhor se adequar à sua satisfação, aos seus interesses, ao seu egoísmo, mola propulsora de sua existência.

Para Schopenhauer, muitas vezes pressentimos secretamente o poder insofismável da vontade; ao tomarmos uma decisão, contudo, duvidamos se a iremos cumprir. Por quê? Porque a certeza final só chega com a efetiva execução da resolução, decidida em última instância pela vontade. Diz o filósofo:

se concebemos uma grande e audaz resolução - que como tal é, propriamente falando, apenas uma promessa da vontade ao intelecto -, permanece freqüentemente, no nosso íntimo, uma dúvida leve e inconfessa ... se nós, na execução, não vamos vacilar ou recuar, em vez de ter firmeza e perseverança na sua execução. É preciso o fato, para convencermos a nós mesmos da franqueza da decisão (Schopenhauer, 1972a, §19, p.236). 
E não se pode querer no passado, mas apenas no presente, porque a forma da vida, na qual ela se manifesta, é um eterno presente. Ninguém vive a vida no passado ou no futuro, mas vive-a tão-somente na forma do presente. Esse também é um dos fatores para o autor de $O$ mundo como vontade e como representação ter ironizado o imperativo categórico kantiano, o agir segundo máximas da razão de tal maneira que a nossa ação se torne uma lei universal, pois esse princípio vincula o passado ao futuro, ignorando os apetites volitivos que porventura se coloquem entre eles, isto é, entre a resolução e a sua execução. Conforme Schopenhauer, o que alguém faz, os atos que cada um pratica têm por mola os impulsos, não as máximas racionais. Os atos são obras da vontade, em dado momento perante certos motivos, certos interesses, pois motivo e interesse são conceitos intercambiáveis. E não se pode matematizar os motivos, via exercício de futurologia. A ação do indivíduo se pauta por aquilo que mais lhe convém num preciso momento, pauta-se por aquilo que combina naturalmente com a sua personalidade, que combina com o seu eu em certas circunstâncias, impossíveis de ser quantificáveis e preconcebidas. O homem nunca deixa de ser um animal egoísta, de sentir-se o centro do universo, e o egoísmo apresenta-se como potencialização a mais presente do eu, é uma espécie de iluminar-se pelo interesse, é um sentir-se eterno nos seus direitos de satisfazer os desejos pessoais presentes, e tudo isso justamente porque a Vontade é a coisa-em-si, não só do sujeito, mas de todos os corpos: ela concentra-se "integralmente indivisa em cada fenômeno" (Schopenhauer, 1972b, §28, p.184). Todos se vêem como o centro gravitacional em torno do qual as coisas devem girar. Exigir uma eticidade kantiana, calculada pela razão, que faz a assepsia das inclinações naturais, desprezando os interesses, cometendo assim uma agressão à sensibilidade, é quixotesco para Schopenhauer - com isso pensa-se de modo quimérico na possibilidade de uma ação sem motivo, sem interesse.

É no horizonte dessa polêmica schopenhaueriana que devemos ter em mente o conto "Noite de almirante". Exigir uma fidelidade de Genoveva às suas juras pretéritas, ao contrato de amor celebrado com o marujo Deolindo, antes que este partisse pelos mares para retornar alguns meses depois, é, pelo menos aos olhos de um leitor de Schopenhauer (e Machado o era), pretender que uma artificial e ineficiente máxima moralracional, resquício dos mandamentos bíblicos, valha, sub-repticiamente, como natureza. É pretender que o passado e o futuro afetivos de alguém possam ser vinculados por um imperativo moral. O próprio Deolindo não é lá tão fiel às suas resoluções, portanto não é um caráter absolutamente reto, fiel aos próprios mandamentos. Ao final do conto, mente para os 
amigos que esperavam relatos do seu caso. Desde quando a mentira se adapta à eticidade da não-contradição dos atos? Antes, já havia mentido até mesmo para si, pois resolvera suicidar-se, todavia renunciara à resolução, meramente intelectual, sem assentimento da vontade. E que falar do momento em que as idéias "marinhavam-lhe no cérebro", fazendo-o pensar em esfaquear ou estrangular Genoveva? Idéias, pensamentos inúteis. Se o próprio Deolindo não cumpre as suas resoluções intelectuais, é justamente porque Machado mostra que, lá dentro daquele intelecto, que pactuou com Genoveva e exigia rígido apego à palavra, esconde-se a impossibilidade, intrínseca à natureza humana, de ser primariamente fiel a meros conceitos. Se se é movido por impulsos, sobretudo pelo mais vigoroso de todos, o amoroso - não adianta, a vontade de cada um sempre vence. Deolindo quer de Genoveva o que nem ele mesmo obtém de si: fidelidade a resoluções, fidelidade a meras promessas da vontade, que pretensamente ligariam o passado ao futuro. É como se Deolindo quisesse a todo custo atribuir realidade determinante a três ilusões: (1) a promessa (como se esta pudesse fazer as vezes da natureza) que liga (2) o passado ao (3) futuro. Só que a promessa jamais poderá ocupar o lugar da natureza, ela advém do acidente, do intelecto. E tanto o futuro quanto o passado, os outros dois termos do engano de Deolindo, não existem por si mesmos no que se refere à vida vivida, que é o que importa em coisas do amor, não os devaneios. Como diz uma personagem de Machado, o Jacobina do conto "Teoria do medalhão": "A melhor definição do amor não vale um beijo de moça namorada" (Machado de Assis, 1994, v.2, p.348). Beijo que, se vale mais do que qualquer teoria amorosa, é porque é um beijo real, efetivo, presente, não beijo imaginado. A vida vivida cristaliza-se num corpo-desejo, dando-se apenas no presente. Se os protagonistas de "Noite de almirante" não cumprem suas resoluções, é porque os seus, por assim dizer, caracteres inteligíveis, as suas vontades são aquilo que lhes é mais essencial, nuclear, e não podem ser moldados por decisões do entendimento.

$\mathrm{Na}$ visão schopenhaueriana, em moral vale a descrição, não a prescrição. O bom moralista é o que desnuda os mecanismos do agir humano, ilustrando as relações de convívio. Fica para o leitor a liberdade de haurir daí a lição que lhe convenha. Tese compartilhada, sem dúvida, por Machado; daí não julgar Genoveva nem Deolindo.

Meio pateticamente, o tocante da situação de Deolindo está em que Machado nos mostra um personagem que se iludiu com o pretenso poder do artifício, da consciência sobre o inconsciente, do intelecto sobre a vontade, da promessa sobre a inclinação, enfim, da razão sobre o desejo, como se um contrato de amor, tomado enquanto obrigação eterna, pu- 
desse ser assinado e cumprido nos moldes da moral kantiana, deixando de lado os direitos das inclinações, os direitos da sensibilidade. Deolindo diz que "a gente jura é para isso mesmo; é para não gostar de mais ninguém..." (Ibidem, p.449). Traduza-se: a gente jura é para isso mesmo, é para, se for preciso, até cometer violência à sensibilidade.

A grande ilusão de Deolindo também se ilustra notavelmente no final do conto, quando, ante as perguntas dos marujos ansiosos por relatos da sua aventura, encena seu sucesso, e responde a tudo: "com um sorriso satisfeito e discreto, um sorriso de pessoa que viveu uma grande noite. Parece que teve vergonha da realidade e preferiu mentir" ( p.451).

E o leitor até certo ponto se comove com essa situação patética do infortunado marujo, pois sabe que está sujeito a tal engodo, já que, como ele, é também dual, é intelecto e vontade, é consciência e inconsciente, é, para usar os termos de Schopenhauer, "cabeça" (enquanto sede das representações) e "órgãos genitais" (enquanto foco da vontade). E nessa oposição, avessa a uma superação dialética, transcorre a nossa vida. Em todo o conto, como no pensamento do filósofo germânico, Machado jamais corre o risco de tomar um partido moral, de julgar, mas se limita a descrever os acontecimentos, mostrando que a natureza possui precedência, em ambos os personagens, sobre as juras, e que a vida é vivida exclusivamente no presente: tanto é que Genoveva, seja quando envolvida com Deolindo ou, mais tarde, com José Diogo, que lhe "virou a cabeça", parece gostar sinceramente de ambos: pelo menos não há no conto explícitas e contundentes observações em contrário. No presente em que se dava, $o$ amor que lhe era possivel, enquanto núcleo da vida, que a reproduz, dava-se espontaneamente - embora, com os rodeios que lhe são peculiares, com as suas sublimações, com os seus desvios, os seus apoios nem sempre intrinsecamente amorosos, como no caso do apoio socioeconômico: pois quem duvidaria que a "caboclinha de vinte anos, esperta, olho negro e atrevido", modesta sem dúvida, pois morava com a velha Inácia, não procurou apoio na condição possivelmente mais segura do marinheiro Deolindo, ou na do mascate José Diogo?

Genoveva de algum modo amou a ambos, dentro daquilo que permitia o seu caráter. Em dado momento declara:

Pois, sim, Deolindo, era verdade. Quando jurei, era verdade. Tanto era verdade que eu queria fugir com você para o sertão. Só Deus sabe se era verdade! Mas vieram outras coisas...Veio este moço e eu comecei a gostar dele... (Machado de Assis, 1994, v.2, p.449) 
"Quando jurei era verdade". Leia-se: naquele presente em que se dava, o amor era real, mas, sendo o momento presente aniquilado no fluxo temporal, enquanto passado não-essencial, pode desvanecer-se também a manifestação do amor que nele se dá. E nenhum momento passado retorna na forma de momento presente, justamente porque foi engolfado pelos momentos de tempo posteriores.

"Mas vieram outras coisas..." Leia-se: outros motivos se apresentaram à sua vontade, outros interesses, e ela, vendo-os, inclinou-se para eles, como uma pedra que cai obedecendo à lei da gravidade. Esqueceu Genoveva, em face dos motivos reais, os imaginários, isto é, esqueceu-se das pretéritas juras. $\mathrm{O}$ que havia de em-si nela a compeliu a movimentar-se, a entregar-se ao mascate José Diogo, abandonando Deolindo.

Genoveva não pôde querer no passado, e, em "Noite de almirante", faz as vezes, em termos schopenhauerianos, da vontade cega por satisfação, enquanto Deolindo faz as vezes do intelecto, iludido por promessas muitas vezes não cumpridas. Genoveva/vontade versus Deolindo/intelecto: a estrutura do conto "Noite de almirante" é polar, ele não é o representante de uma dialética que admita uma superação, uma síntese de teses opostas. Machado de Assis era leitor de Schopenhauer, o grande inimigo da dialética pacificadora, e não de Hegel.

BARBOZA, J. L. Schopenhauerian philosophy and Machadian literature: around the short story "Noite de almirante". Trans/Form/Ação (São Paulo), v.23, p.7-17, 2000.

- ABSTRACT: This paper deals with the reception of some elements of Schopenhauerian philosophy, such as the oposition between intellect and will, in the literature of Machado de Assis. Indeed, if we examine the short story "Noite de almirante", we can see that the character Genoveva represents the will, while Deolindo is guided by the intellect.

- KEYWORDS: Schopenhauer; Machado de Assis; intellect; will.

\section{Referências bibliográficas}

MACHADO DE ASSIS, J. M. Memórias póstumas de Brás Cubas. Rio de Janeiro: Lia/Editor S. A., s. d.

. Obra completa. Rio de Janeiro: Nova Aguilar, 1994.

SCHOPENHAUER, A. Ergänzungen. In:__. Die Welt als Wille und Vorstellung. Wiesbaden: F. A. Brockhaus, 1972a.

. Die Welt als Wille und Vorstellung. Wiesbaden: F. A. Brockhaus, 1972b. 